\title{
Development of Bead Modelling for Distortion Analysis Induced by Wire Arc Additive Manufacturing using FEM and Experiment
}

\author{
Keval P Prajadhiama ${ }^{1}$, Yupiter HP Manurung ${ }^{1}$, Zaidi Minggu ${ }^{1}$, Fetisia HS Pengadau ${ }^{1}$, Marcel Graf ${ }^{2}$, Andre Haelsig $^{3}$, \\ Tom-Eric Adams ${ }^{3}$ and Hui Leng Choo ${ }^{4}$ \\ ${ }^{1}$ Faculty of Mechanical Engineering, UiTM Shah Alam, Selangor, Malaysia \\ ${ }^{2}$ Professorship of Virtual Production Engineering, Chemnitz University of Technology, Chemnitz, Germany \\ ${ }^{3}$ Chair of Welding Engineering, Chemnitz University of Technology, Chemnitz, Germany \\ ${ }^{4}$ Taylor's University, Malaysia
}

\begin{abstract}
In this research, Wire Arc Additive Manufacturing is modelled and simulated to determine the most suitable bead modelling strategy. This analysis is aimed to predict distortion by means of thermomechanical Finite Element Method (FEM). The product model with wire as feedstock on plate as substrate and process simulation are designed in form of multi-layered beads and single string using MSC Marc/Mentat. This research begins with finding suitable WAAM parameters which takes into account the bead quality. This is done by using robotic welding system with $\varnothing 1.2 \mathrm{~mm}$ filler wire (AWS A5.28 : ER80SNi1), shielding gas $\left(80 \% \mathrm{Ar} / 20 \% \mathrm{CO}_{2}\right)$ and $6 \mathrm{~mm}$-thick low carbon steel as base plate. Further, modelling as well as simulation are to be conducted with regards to bead spreading of each layers. Two different geometrical modelling regarding the weld bead are modelled which are arc and rectangular shape. Equivalent material properties from database and previous researches are implemented into simulation to ensure a realistic resemblance. It is shown that bead modelling with rectangular shape exhibits faster computational time with less error percentage on distortion result compared to arc shape. Moreover, by using the rectangular shape, the element and meshing are much easier to be designed rather than arc shape bead.
\end{abstract}

\section{Introduction}

Wire-arc additive manufacturing (WAAM) can be explained as a modern competitive method of metallic parts fabrication with complicated structure and geometries which based on multi-layer multi-bead (MLMB) parts. Comparing WAAM against similar technologies, WAAM is able to produce parts in shorter times (time-efficient) and with relatively lower costs (cost-competitive). As a powerful method, this technology uses electric arc to melt metallic wire and can achieve a high feed rate [1] The WAAM denomination gathers various techniques for metallic parts manufacturing, which can be distinguished by the nature of the energy source allowing the metal deposit or densification, and by the form of the raw material [2]

The production of high-grade alloy components by direct metal deposition shows considerable promise for industrial application in the manufacturing environment. [3].Nowadays, Additive Manufacturing methods, using powder as a consumable, are also used widely alongside with the additive manufacturing which involves metal wire [4].

Motion system, heat source and feedstock are common elements exists in a basic Additive Manufacturing or WAAM system. Due to AM's distinct characteristic on each types of process they could be applied for a comprehensive application regarding to the specialties of each processes. For example, selective laser melting delivers net shape components with high resolution; however, similarly to electron beam melting, deposition rates are relatively low, and part size is limited by the enclosed working envelope [5].

The heat propagation in GMAW-based additive manufacturing is highly non-linear transient thanks to the existence of multiple fusion, solidification, and phase transformation [6]. Parameters assigned within the welding process possesses a significant influence towards the geometry resulted from weld beads, of which these geometries in turn bring an influence towards the properties of welded structure [7]. Bead modelling, on one hand controls the path planning variables. On the other hand, it defines the suitable weld setting which corresponds the desired shape of bead geometry [8].

The simulation of WAAM processes is usually carried out in analogy to the techniques used in multipass welding simulations: basically, a transient thermomechanical FE analysis is carried out, simulating the heat transfer to the work piece by means of heat source model. Even though some works focuses on molten pool and arc dynamics simulation, it's not possible to apply such complex techniques at component scale level due to the unacceptable computational time requirements [9]. 
On the FEM simulation which models the WAAM, the heat transfer from the arc to the molten pool is simulated using a heat source model, which prescribes a heat generation per unit volume in the molten pool region. Despite FE analysis delivers an accuracy and effectiveness on analyzing AM process, the complexity of WAAM process in term of designs is often connected with the relatively large FE model with the needs of high computational time required on running the simulation [10].

Due to its rapid and spatially variable cooling and heating, the additively manufactured goods are often distorted and prone to residual stresses. It should be noted that such criticalities would influence all metal AM technologies, since they are caused by the nonuniform temperature field in the part during the manufacturing process [11]. Welding distortions appears to negatively affect the external appearance, dimension accuracy and other conditions such as various strength of the structure. By doing the real welding process, it will lead into a quite sums of schedule delay and additional costs caused by doing reworks [12].

Finite element modelling (FEM) can be utilized to analyze the deformation issues such as distortion and residual stresses, allowing for more advanced planning in early stage of WAAM planning in order to avoid costly reworks. The usage of FEM to analyze distortion in WAAM originates from the prior researches performed on multi-pass welding [13].

Many researches since the last decade [14-16] had performed analysis regarding to welding distortion cases. In this research, a method development on predicting the deformed state of WAAM will be investigated by utilizing FEM analysis in a form of multi-layered process. The good agreement between the results obtained from FEM simulation and experimental process along with computational time are main objectives in this investigation

\section{Simulation using Nonlinear FEM Software}

The proposed analysis for this research in which concerns about distortion of WAAM is executed by means of two-step approaches: FE simulation and Experimental study. The former was executed in order to make a prediction of distortion while the latter is executed in order to validate the FEM simulation's results, should the results from both approaches meets a good agreement with a small margin of error, the primary objective of this research is accomplished. This first section explains the details of FEM simulation which deals with the following aspects:

1. Geometrical and material modelling,

2. Heat source modelling,

3. Process Simulation.

MSC Marc/Mentat is chosen as the FEM software for this research simulation procedure of which is displayed on figure 1 below.

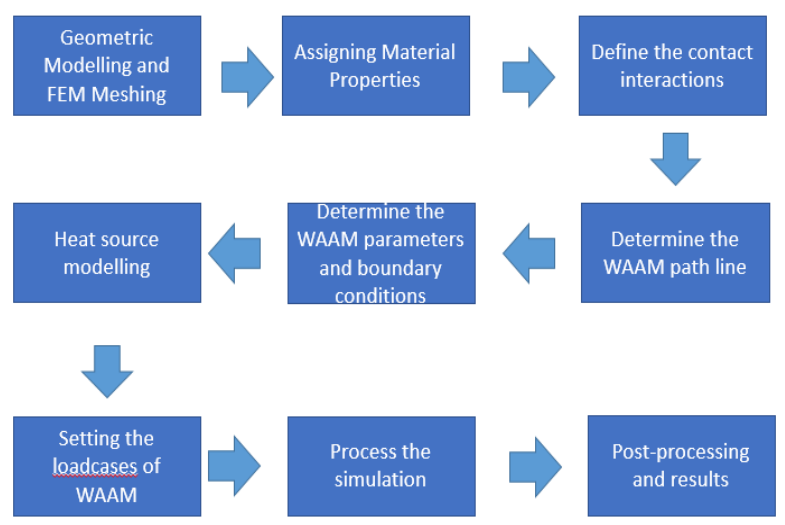

Fig. 1. WAAM simulation procedure using MSC Marc/Mentat

Since the WAAM simulation requires a multi-pass WAAM sequence, the numbers of similar procedures which are identical to the procedure displayed on Figure 1 should be repeated depends on layers in WAAM simulation. In this research, a 10 layers of WAAM beads is implemented indicating the numbers of procedures that should be repeated 10 times before move on to the load cases setting.

\subsection{Geometrical and Material Description of FEM Simulation}

The modelled substrate possesses the dimension of 200 $\mathrm{mm} \times 50 \mathrm{~mm} \times 6 \mathrm{~mm}$ which mirrors the actual Low Carbon Steel substrate that would be used later on experimental process. For filler, a model with $160 \mathrm{~mm}$ of length along with $\varnothing 1.2 \mathrm{~mm}$ is modelled. The basic FEM model for this multi-layer WAAM is exhibited by figure 2.

Mesh pattern is needed in order to achieve meshzoning for both substrate and filler. For this FEM simulation, mesh direction in particular direction is selected, which each zone is discretized using hexahedral elements in uniform mesh. A finer mesh is applied on the region near the weld bead for an enhanced visualization of heat transfer near said areas.

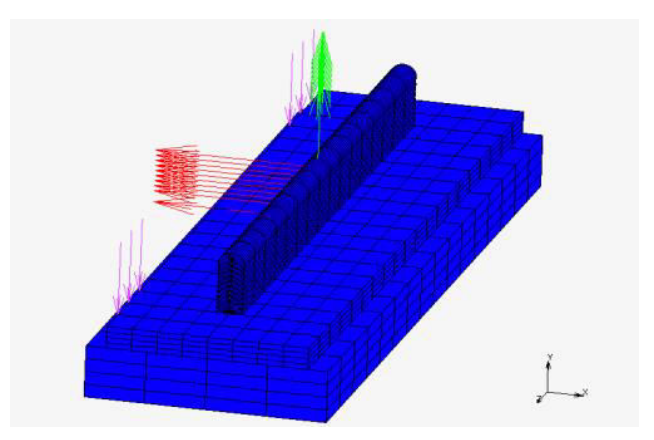

Fig. 2. Finite element model of 10 layers WAAM displayed by MSC Marc/Mentat 
A bead modelling on WAAM design is crucial in order to produce a metal parts with a high degree of geometrical accuracy and smoothness. Single-bead modelling with bead spacing taken into a consideration is adapted for the bead modelling of FEM simulation for this research. Two bead modelling strategies are used for this research; one is bead modelling which utilizes a complex, arc shape, and the second bead modelling strategy utilizes a much simpler rectangular shape. Both of the bead modelling strategies shares the same measurements in term of height and width which both are modelled based on the real bead produced by WAAM experiment.

A sample of bead geometry which is sketched for FEM simulation can be seen in Figure 3, which features 2 different meshing strategies.

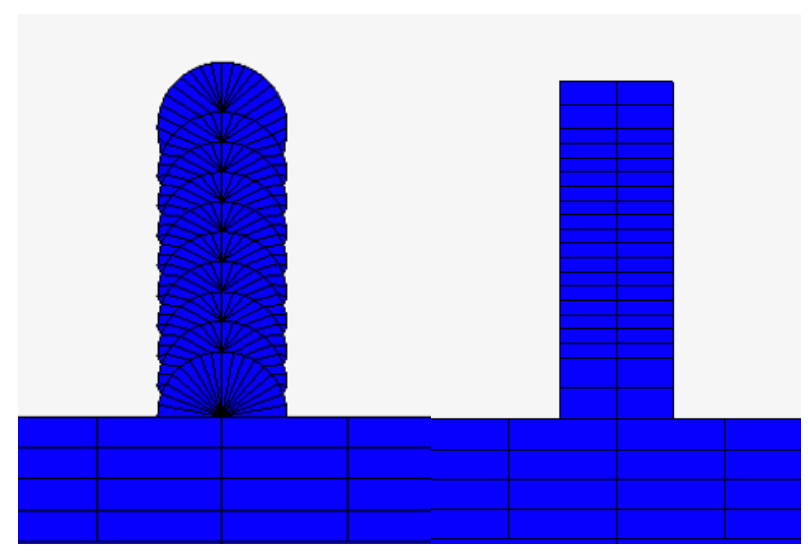

Fig. 3. Bead modelling for FEM model with different geometrical modelling; Arc shape (left) and Rectangular shape (right)

This simulation assigns High Strength Low Alloy Steel (HSLA) type of material as both filler and substrate material. The usage of HSLA generally can be found in power plant components, civil structures and pipelines, the HSLA is suitable for those equipment due to HLA's outstanding mechanical properties in term of toughness and strength. Previous researches which involved the usage of HSLA on WAAM processes [18-19] has proven that this type of material has an outstanding weld ability during process.

In this simulation, HSLA S460 is chosen as filler material while low carbon S235 is assigned as substrate material. The physical properties for both bead and substrate materials are imported into FEM simulation [20]. Figure 4 and 5 displays the material assigned for the FEM simulation with temperature dependency.

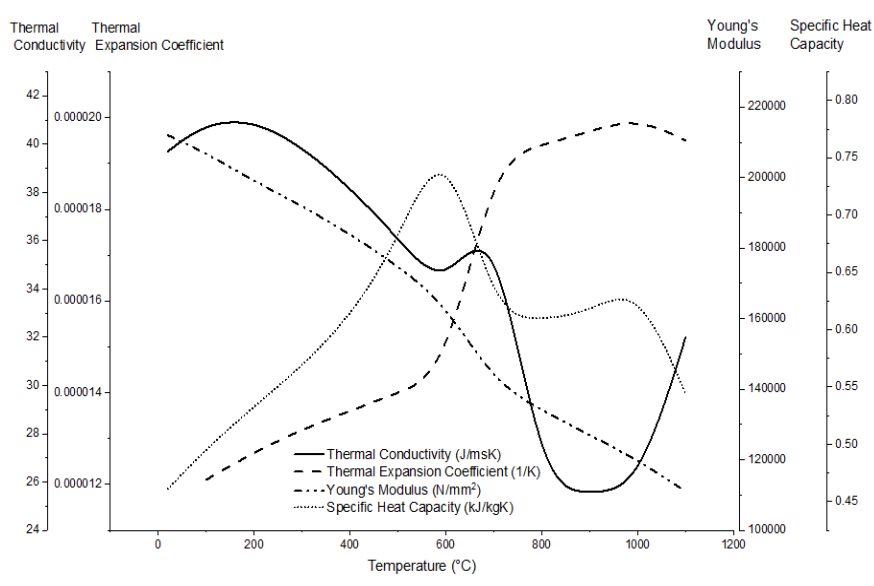

Fig. 4. Temperature-dependent thermo-physical properties of S460

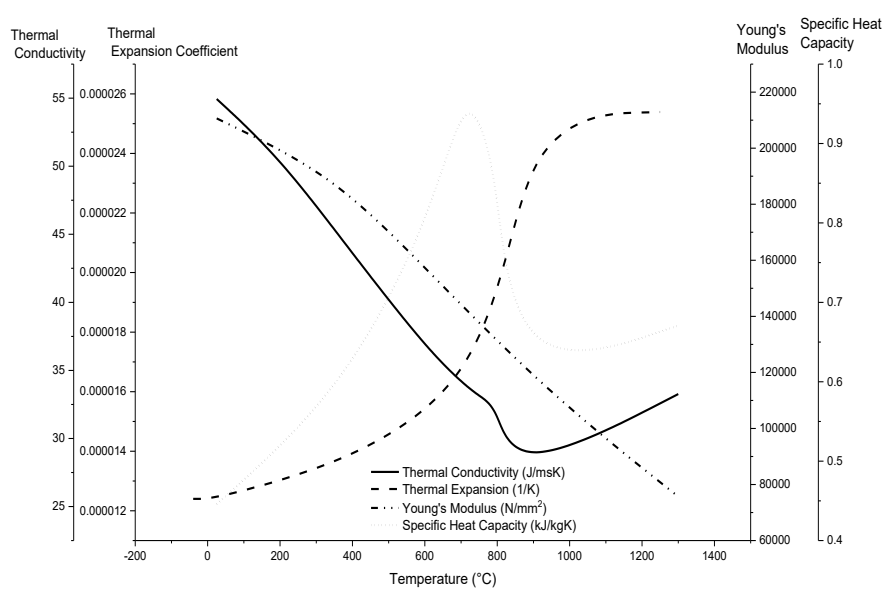

Fig. 5. Temperature-dependent thermo-physical properties of S235

\subsection{Heat Source modelling of FEM simulation}

To produce a reliable result, an appropriate heat source model along with its dimension needs to be assigned in agreement with the overall condition of planned process. In this research, the Goldak's double ellipsoid model represents the state of the art of WAAM [21]. Goldak's double ellipsoid, which is an offered heat source model advocates the heat input as a function to generate heat while also able to control the amount of overall power delivered into substrate and filler. .Figure 6 illustrates the Goldak's Double Ellipsoid model. Heat source modelling is one of the challenge on a WAAM simulations, whether it's a single or multi-layered WAAM process. 


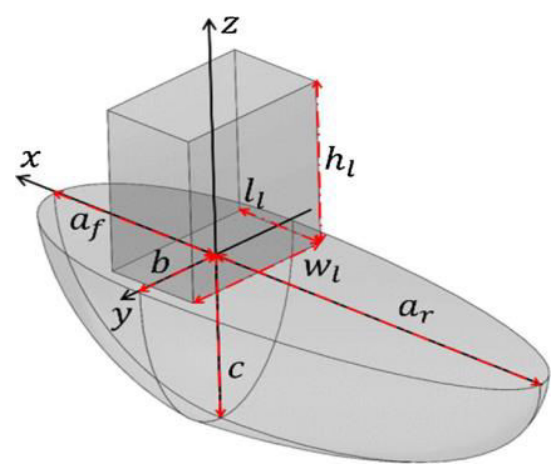

Fig. 6. Illustration of Goldak's Double Ellipsoid Heat Source Model

Since the Goldak heat source introduces a Gaussian distribution which was introduced by Pavalec in 1960s. This model incorporated the heat below the welding rc resulting an accurate simulation for deep and shallow penetration.

The power density of the heat flux in front section $\left(\mathrm{Q}_{\mathrm{vf}}\right)$ of heat source can be determined by following formula $(\mathrm{Eq} 1)$ :

$q_{v f}(x, y, z)=\frac{6 \sqrt{3} f_{f} Q}{a b c_{f} \pi \sqrt{\pi}} e^{-3 \frac{x^{2}}{a^{2}}} \cdot e^{-3 \frac{y^{2}}{b^{2}}} \cdot e^{-3 \frac{x^{2}}{c^{2}}}$

And the power density of the heat flux in rear section $\left(\mathrm{q}_{\mathrm{vr}}\right)$ is established by $(\mathrm{Eq} 2)$ :

$q_{v r}(x, y, z)=\frac{6 \sqrt{3} f_{r} Q}{a b c_{r} \pi \sqrt{\pi}} e^{-3 \frac{x^{2}}{a^{2}}} \cdot e^{-3 \frac{y^{2}}{b^{2}}} \cdot e^{-3 \frac{z^{2}}{\zeta_{T}}}$

Where $f_{f}$ and $f_{r}$ are the heat deposited fractional factors in the front and rear quadrant respectively and its sum is equal to 2. The distribution of fluxes in the double ellipsoid model is determined by 4 directions: Width (b), Depth (d), Rear Length (ar) and Front Length (af). The values for each direction used in WAAM simulation are shown in Table 1 , the dimensions are differed depending on the size of the weld bead.

Table 1. Heat Source Dimension in Simulation

\begin{tabular}{|c|c|c|}
\hline $\begin{array}{c}\text { Heat Source } \\
\text { dimensions }\end{array}$ & $\begin{array}{c}\text { Value } \\
\text { (Small bead) }\end{array}$ & $\begin{array}{c}\text { Value } \\
\text { (Large bead) }\end{array}$ \\
\hline Width (mm) & 4 & 5 \\
\hline Depth (mm) & 3.2 & 5.3 \\
\hline $\begin{array}{c}\text { Rear Length } \\
(\mathrm{mm})\end{array}$ & 2.4 & 3.5 \\
\hline $\begin{array}{c}\text { Front Length } \\
(\mathrm{mm})\end{array}$ & 2.4 & 3.5 \\
\hline
\end{tabular}

\subsection{Heat Source modelling of FEM simulation}

Table 2 displays the parameters that are implemented on the simulation process that would be later used on the experimental verification. The Current (I) and the Voltage (V) are considered under the equation of power in MSC Marc/Mentat. Latent heat, solidus and liquidus temperature are adjusted according to actual thermal properties of HSLA material data and they are instigated under material properties section of MSC Marc/Mentat.

Table 2. WAAM parameters used in MSC Marc WAAM simulation

\begin{tabular}{|c|c|}
\hline WAAM Parameter & Value \\
\hline Current, I (A) & 100 \\
\hline Voltage, V (V) & 16 \\
\hline Travel Speed, $\mathrm{v}(\mathrm{mm} / \mathrm{s})$ & 4 \\
\hline
\end{tabular}

\section{Experimental Set-up and Procedures}

For the purpose of experimentation, a comprehensive WAAM experiment was executed using the welding facility installed in the manufacturing lab of the Faculty of Mechanical Engineering, UiTM Shah Alam. Specimen of commercially sourced low Carbon steel plate with dimensions $200 \mathrm{~mm} \times 50 \mathrm{~mm}$ x $6 \mathrm{~mm}$ were used to form the substrate onto which weld beads were deposited using ER80S-Nil wire with a diameter of $1.2 \mathrm{~mm}$. Table 3 below shows the chemical composition for the materials used throughout the experimental process.

Table 3. Chemical compositions of S235 and ER80S-Ni

\begin{tabular}{|l|c|c|c|c|c|}
\hline \multirow{4}{*}{ Low carbon steel S235 } & $\mathrm{C}$ & $\mathrm{Si}$ & $\mathrm{S}$ & $\mathrm{Cr}$ & $\mathrm{Cu}$ \\
\cline { 2 - 6 } & 0.22 & 0.05 & 0.05 & - & - \\
\cline { 2 - 6 } & $\mathrm{Mn}$ & $\mathrm{P}$ & $\mathrm{Ni}$ & $\mathrm{Mo}$ & \\
\cline { 2 - 6 } & 1.60 & 0.05 & - & - & \\
\hline
\end{tabular}

\begin{tabular}{|c|c|c|c|c|c|}
\hline \multirow{4}{*}{ ER80S-Ni } & $\mathrm{C}$ & $\mathrm{Si}$ & $\mathrm{S}$ & $\mathrm{Cr}$ & $\mathrm{Cu}$ \\
\cline { 2 - 6 } & $0.07-0.12$ & $0.4-0.80$ & 0.02 & 0.15 & 0.35 \\
\cline { 2 - 6 } & $\mathrm{Mn}$ & $\mathrm{P}$ & $\mathrm{Ni}$ & $\mathrm{Mo}$ & \\
\cline { 2 - 6 } & $1.0-1.50$ & 0.020 & $0.80-1.10$ & 0.15 & \\
\hline
\end{tabular}


ABB IRB 2400/16 is the robotic welding machine used for this experimental process equipped with GMAW power source KEMMPI Pro Evolution ProMIG 540MXE. Figure 7 exhibits the said robotic welding machine used in experiment

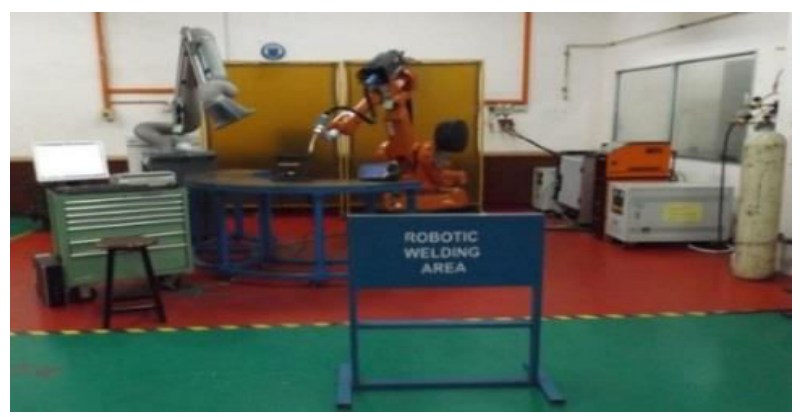

Fig. 7. ABB IRB 2400/16 Robotic welding Machine

A shielding gas which value is stated on following table is involved on each welding sections. For this research, common input parameters of the GMAW welding process consists of voltage (V), arc current (I), travel speed (TS) and wire feed speed ratio (WFSR) were adjusted to be differentiated in order to characterise the geometry of deposited weld beads. The adjusted bead-dependent welding parameters are exhibited in Table 4.

Table 4. Assigned parameters for experimental process

\begin{tabular}{|c|c|}
\hline Experiment Parameter & Value \\
\hline Current, I (A) & $100-110$ \\
\hline Voltage, $\mathrm{V}(\mathrm{V})$ & $15-16$ \\
\hline Travel Speed, $\mathrm{v}(\mathrm{mm} / \mathrm{s})$ & 4 \\
Wire feed speed ratio $(\mathrm{m} / \mathrm{min})$ & 2.2 \\
\hline Shielding gases $\left(\mathrm{Ar} / \mathrm{CO}_{2}\right)$ & $80 \%, 20 \%$ \\
\hline
\end{tabular}

The work piece distortions were measured by utilizing Mitutoyo Euro Apex C776 CMM (Coordinate Measurement Machine), the work-piece was scanned before and after the deposition in order to concerns the base plate unevenness in comparing the distortions. Three measuring points of the joint were established in order to have the CMM machine detect the distortion on certain point that are going to be analyzed.

The specimen would later cut in a smaller specimen using abrasive cutter machine. Smaller specimen that resulted from abrasive cutting process would later be grinded, polished and etched prior to Macrograph section. Below is the Macrograph result of the 10 layers WAAM experiment generated by light macrograph and demonstrated in figure 8 .

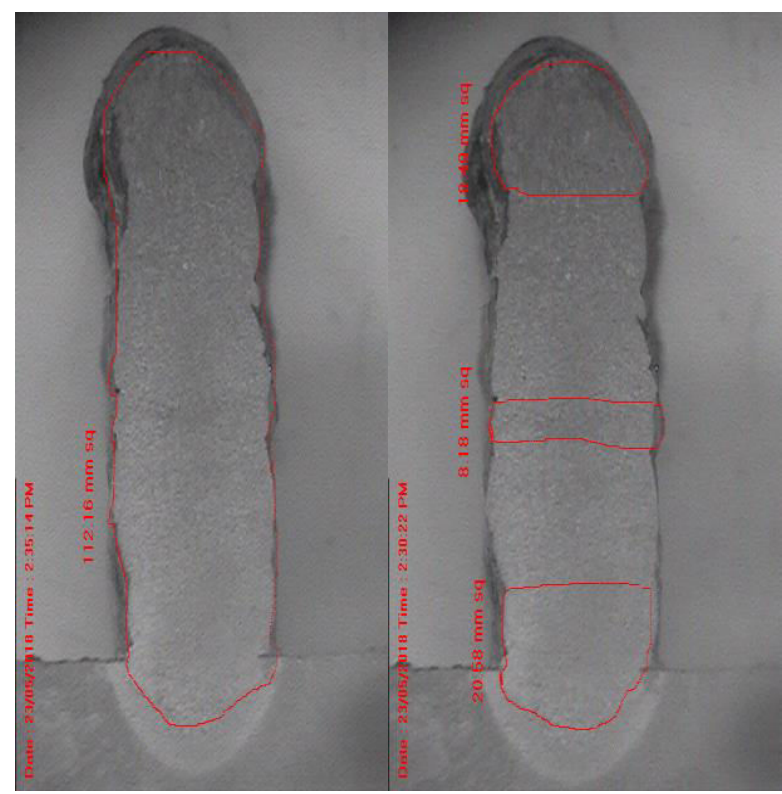

Fig. 8. Macrograph results of 10 layers WAAM experiment

The size of an area measured by the macrograph result are chosen as the guidelines for FEM modelling and it is applied on both bead modelling strategies which have been mentioned in previous sections. This would ensure the similarities between real weld bead produced by WAAM experiments and bead which are modelled using MSC Marc/Mentat

An approximate $100 \mathrm{~N}$ force of clamping towards $\mathrm{Y}$ axis is placed on the left side of the specimen in order to examine the distortions on the unclamped side of the substrate which already been measured by CMM machine. Along with the macrograph result, the exact clamping condition is also applied on FEM simulation. Figure 9 exhibits the real clamping conditions of WAAM experiment.

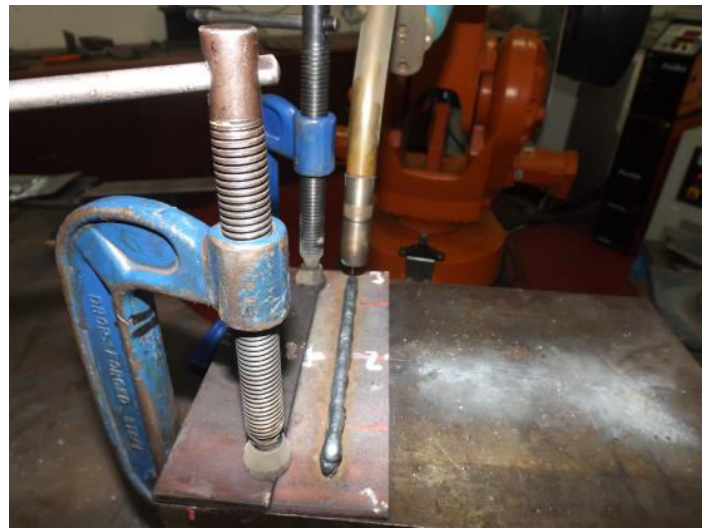

Fig. 9. Real clamping condition which applied on experimental process 


\section{Results and Discussions}

The distortion result produced by the experimental process is displayed on figure 10 below.

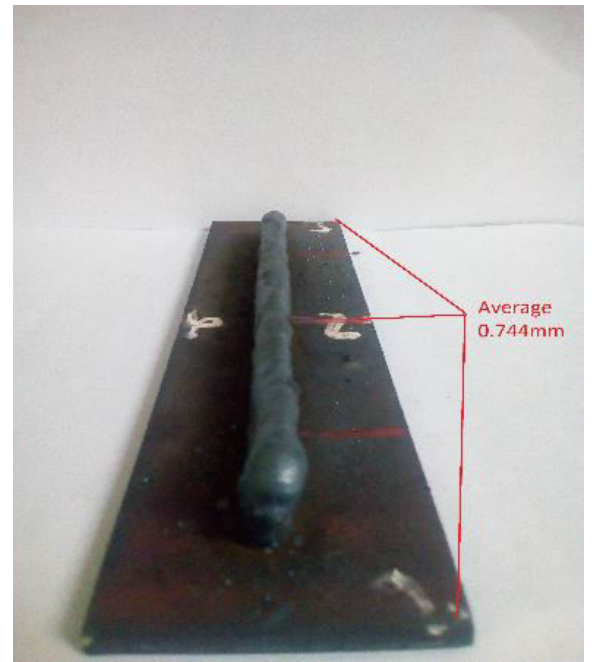

Fig. 10. Distortion resulted by 10 layers WAAM experiment

Figure 11 and 12 demonstrates the angular distortion results towards the displacements of both arc and rectangular bead modelling model of FEM simulation. The visualization set in MSC Marc/Mentat is Contour Band setting view and it is applied for bead modelling.

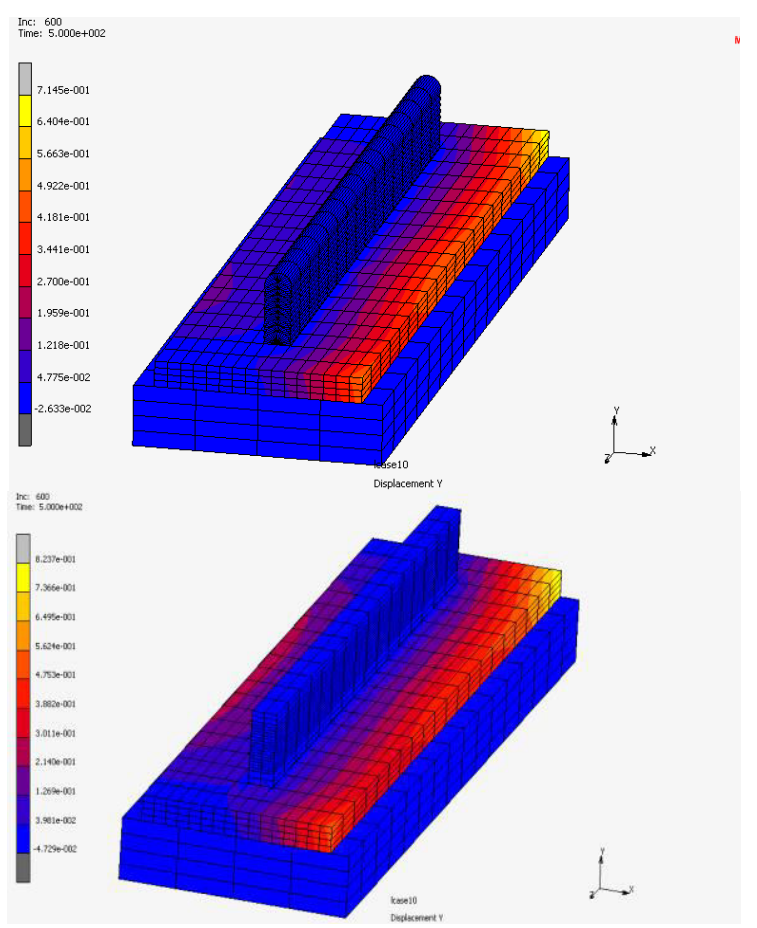

Fig 11-12. Distortion results displayed by FEM simulations which covers: Arc shape bead (Top) and Rectangular shape bead (bottom)
By looking at these pictures, the distribution of displacements on the weldment surface can be examined through the contour shape and colors in a weld specimen. The table acts as the fixed displacement on both $\mathrm{x}$ and $\mathrm{z}$ axis under the plate which determines the bearing condition of the weldment and its applied for both simulations The number that were gathered for the experiment result are from the measurement machine (CMM). By utilizing CMM, the percentage of distortion in certain nodes were calculated, the same nodes also pointed in the FEM simulation. Three points are selected as a tracking points for measurement of which the average value of the three distortions value will serves the benchmark of comparison.

The Table 5 exhibits the differences value in distortions resulted in substrate between experimental result and FEM simulation results along with their respective relative error percentage against experimental result.

Table 5. Distortion results of experimental process and FEM simulation

\begin{tabular}{|l|l|l|l|l|}
\hline \multicolumn{2}{|l|}{$\begin{array}{l}\text { Average distortion } \\
(\mathrm{mm})\end{array}$} & \multicolumn{2}{l}{$\begin{array}{l}\text { Relative } \\
\text { percentage }(\%)\end{array}$} \\
\hline \multirow{2}{*}{$\begin{array}{l}\text { Experimen } \\
\mathrm{t}\end{array}$} & \multicolumn{2}{|c|}{ Simulation } & \multirow{2}{*}{$\begin{array}{l}\text { Arc } \\
\text { Shape }\end{array}$} & $\begin{array}{l}\text { Rectangular } \\
\text { Shape }\end{array}$ \\
\cline { 2 - 3 } 0.74 & $\begin{array}{l}\text { Arc } \\
\text { Shape }\end{array}$ & $\begin{array}{l}\text { Rectangul } \\
\text { ar Shape }\end{array}$ & $\mathbf{2 0}$ & $\mathbf{1 7 . 3}$ \\
\hline
\end{tabular}

A computational time for both bead modelling strategies is also compared. Computational time for both simulation is an overall time consumed from start to end of the FEM simulation. Table 6 exhibits the comparison of total computational time of two different bead modelling.

Table 6. Total computation time of two FEM simulations

\begin{tabular}{|l|l|l|}
\hline Bead Modelling & $\begin{array}{l}\text { CPU-Time } \\
(\mathrm{s})\end{array}$ & $\begin{array}{l}\text { Relative } \\
\text { Percentage } \\
\text { Difference [\%] }\end{array}$ \\
\hline Arc Shape & 924 & - \\
\hline Rectangular shape & 813 & $12 \%$ \\
\hline
\end{tabular}

\section{Conclusion}

Through the Finite Element Method, a study of distortions of 10 Layers WAAM had been executed. The research covers both numerical and experimental analysis which was compared as final output of this research. To conclude this research, there are some crucial points that will be explained by following statements:

1. The FEM analysis of WAAM model were executed successfully and the simulation procedure is clear as well as structured, 
2. Simulation using MSC Marc/Mentat shows good agreement on distortion tendency compared to the results of experiment with relative percentage error up to only $20 \%$,

3. The rectangular shape bead modelling displays a lower error percentage compared to arc shape one, which only a slight difference with both simulations still within acceptable range in term of error percentage,

4. Rectangular shape bead modelling FEM simulation also exhibits a faster computational time which caused by a simpler meshing in overall results in lower elements to be calculated,

5. The non-homogeneous material and geometry along with pre-condition of WAAM process are a factor that might cause the difference between experimental and simulation results.

As further recommendation, a rectangular shape heat source model should be considered regarding to the rectangular shape bead modelling and should be investigated instead of utilizing Goldak's double ellipsoid model. Furthermore, the temperaturedependent properties of filler material should be created instead of using equivalent existing material.

The authors would like to express their gratitude to staff member of Welding Laboratory, Advanced Manufacturing Technology Centre at Faculty of Mechanical Engineering, Universiti Teknologi MARA (UiTM) for encouraging this research. This research was conducted under international cooperation with Professorship of Virtual Production Engineering and Chair of Welding Engineering at Chemnitz University of Technology in Germany supported by international research grant of DAAD (Ref. $\mathrm{Nr}$ : 57347629). This research is also financially supported by Geran Inisiatif Penyeliaan (GIP) from Phase 1/2016 with Project Code: 600-IEMI/GIP 5/3 (0019/2016).

\section{References}

1. Yong Zhe L, Yunfei S, Qinglin H, GuanjungZ,Imre H., "Enhanced beads overlapping model for wired arec additive manufacturing of multi-layered bead metallic parts", Journals of Material Processing Tech. pp, 838-484, (2018)

2. Gomez O A, Corona GA, Deschaux-Beaume F, Mezrag B, Rouquette S., "Effect of parameters on the quality of allumunium alloy AL55Si deposits in wire arc additive manufacturing using a cold metal transfer process", Science and Technology of Welding and Joinning, (2017)

3. Hussein N, Segal J, McCartney D.G, Pashby IR., "Microstructure formation in waspalloy multilayer builds following direct metal deposition with laser and wire", Materials Science and Engineering A 497, pp. 260-269, (2008)
4. Gieorgij G, Walery K, Irena M., "Peculiarities of simulation of the additive process of forming 3D products from steel 09G2S", Article September, (2017)

5. S.W Williams, Martina F. Addison A.C, Ding J, Pardal G, Colegrove P., "Wire+Arc Additive Manufacturing", Materials Science and Technology, (2015)

6. Jun Xiong, Rong Li, Hui Chen., "Heat propagation of circular thin-walled parts fabricated in additive manufacturing using gas metal arc welding", Journal of Material Processing Technology, Volume 251. pp, 12-19, (2018)

7. Hoye NP, Appel EC, Cuiuri D, Li H., "Characterisation of metal decomposition during additive manufacturing of Ti-6Al-4v by arc wire methods", Defense material technology centre, University of Wollongong, Australia, (2018)

8. Donghong D, Dominic C, Huijun L, Stephen D, Natha L., "Bead modelling and implementation of adaptive MAT path in wire arc additive manufacturing", Journal of Material Processing Technology, Volume 251, pp. 34-40, (2018)

9. Fillipo M, Giuseppe V, Antonio S, Gianni C. Finite element modelling of wired-arc additive manufacturing process. Procedia CIRP, Volume 55, pp. 109-114, (2016)

10. Montevecchi F, Grossi N, Takagi H, Scrippa A, Sasahara H., "Campatelli G. Cutting forces analysus in additive manufactured AISI H13 alloy", Procedia CIRP, (2016)

11. Filippo M, Niccolo G, Giuseppe v, Antonio S, Gianni Campatelli., "Finite Element mesh coarsening for effective distortion prediction in Wire Arc Additive Manufacturing. Additive Manufacturing 18”, pp. 145-155, (2017)

12. Lidam Robert Ngendang, et al., "Simulation study on multi-pass WELDING distortion of combined joint types using thermo-elastic-plastic FEM", The Journal of Engineering Research, (2012)

13. Denlinger Erik R, Michaleris P., "Effect of stress relaxation on distortion in additive manufacturing process modelling", Additive Manufacturing 12, pp. 51-59, (2016)

14. Paul AC, Jack D, Fillomeno M, Jianglong G, Philip P, Jan H., "Application of bulk deformation methods for microstructural and material property improvement and residual stress and distortion control in additively manufactured components", Scripta Materialia, Volume 135, pp. 111-118, (2017)

15. Jianglong G, Xiaoshu W, Jing B, Jialuo D, Stewart W, Yuchun Z, Khun L., "Deformation microstructures and strengthening mechanisms for the wire arc additively manufactured Al-Mg4.5mn alloy with inter-layer rolling", Material Science and Engineering: A, Volume 712, pp. 292-301, (2018) 
16. Jun X, Yanjiang L, Rong L, Ziqiu Y.," Influences of process parameters on surface rougness on multi-layer single-pass thin-walled pars in GMAWbased additive manufacturing.", Journals of Materials Processing Technology, Volume 252, pp.128-136, (2018.)

17. Yi S, Chen xi L, Zesheng Y, Huijun L, Yongchan L., "Formation mechanism and control methods of acicular ferrit in HSLA steel: A review", Journals of Materials Science and Technology, (2017)

18. Liangyun L, Xiangwei K, Chunlin Q, Dewen Z., "Influence of microtstructural aspects on impact toughness of multi-pass submerged arc welded HSLA steel joints", Materials and Design. Volume 90, pp. 488-498, (2016)

19. Houman Ali P, Anna P, Reza Ghomaschi, Mark R., "Investigating the effects of welding process on residual stresses, microstructure and mechancal properties in HSLA steel welds", Journal of Manufacturing Processeses. Volume 28, pp. 70-81, (2017)

20. Manurung, Y.H.P., "Database of Common Material Properties", (to be published), (2015)

21. J. Goldak, A. Chakravarti, M. Bibby., "A new finite element model for welding heat sources", Metal rans. B 15, pp. 299-305, (2014) 